\title{
Inhalt
}

\section{Abkürzungen $-\mathrm{XI}$}

Einleitung - 1

Quellen - 17

Aufbau der Arbeit -18

Prinzipien -22

Geschärfte Gedanken - Abgestumpfte Gefühle — $\mathbf{5 2}$

Die doppelte Aufgabe: Verwoerds Masterarbeit von $1922-66$

Verwoerds Dissertation -74

Entwicklung - 87

Aufbaustudium in Deutschland - 87

Der Aufenthalt in den USA $1927-101$

Professor Verwoerd - 103

Apartheid und Entwicklung - 121

Von der Soziologie zur Sozialpolitik - 130

Engagement für die „poor whites“_ 130

Der Übergang in die Politik — 142

Verwoerd als Intellektueller $-\mathbf{1 6 0}$

Propaganda -166

Der Journalist — 166

Propaganda-Techniken — 174

Verwoerd als Redner - 181

Logik als rhetorisches Mittel — 185

Organisierte Volkseinheit — 195

Volkseinheit: Organisierter Nationalismus — 197

Der Kriegsausbruch und das Scheitern der „Hereniging“ — 200

Der Afrikaner Broederbond - 203

Der Kampf gegen die Ossewabrandwag — 214

Nachkriegszeit - 224

„Hereniging“— 226 
Chaos und Ordnung -231

Differenz und Reinheit -252

Verwoerds Antisemitismus -274

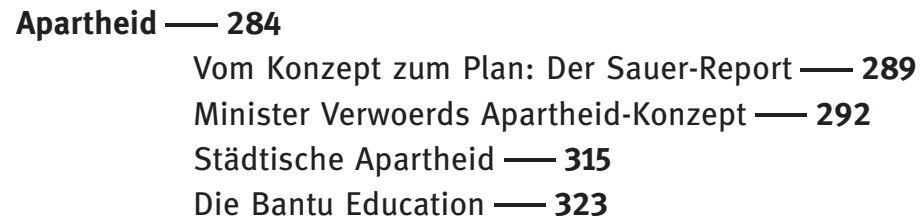

Wissen und Nichtwissen - Die geisteswissenschaftlichen Begründungen der Apartheid — 331

Völkerpsychologie - 332

Ethnologie - 337

Geschichte 355

Homelands -364

Premierminister Verwoerd - 364

Die Homelandpolitik - 367

Der Republikaner auf dem Siegespfad — 376

Vom Kulturnationalismus zum Nation-Building — 397

Südafrika und der weltweite Rassenkonflikt — 403

Repression und Kontrolle - 413

Repression gegen politische Gegner - 414

Umgang mit der Presse -425

Dialogverweigerung — 426

Konflikte mit den englischen Kirchen - 429

Inder und Coloureds -437

Modernisierung - 459

Der Orange River Dam $-\mathbf{4 8 0}$

Der Todeshauch — 492

„Der Hauch des Todes“ $\mathbf{5 1 0}$

Schluss -521 
Bibliographie - 530

Archive - $\mathbf{5 3 0}$

Literatur — 533

Personenregister -607

Ortsregister - 611

Sachregister -612 
